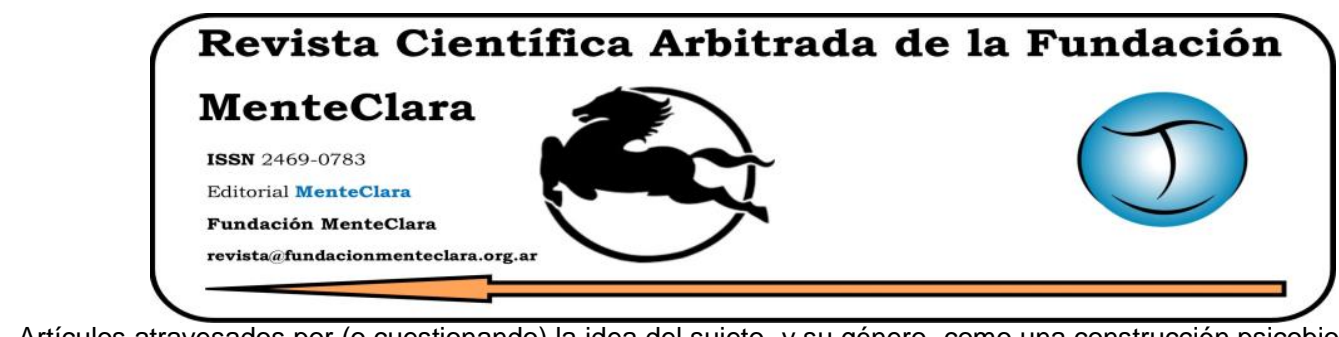

Artículos atravesados por (o cuestionando) la idea del sujeto -y su género- como una construcción psicobiológica de la cultura. Articles driven by (or questioning) the idea of the subject -and their gender- as a cultural psychobiological construction

Vol. 2 (1), 2017

ISSN 2469-0783

https://datahub.io/dataset/2017-2-1-e23

\title{
ANÁLISIS CRÍTICO DEL KULARNAVA TANTRA -PARTE 1- UN PRÓLOGO VICIADO DE SEXUALIDAD REPRIMIDA
}

\author{
CRITICAL ANALYSIS OF THE KULARNAVA TANTRA -PART I- A FOREWORD \\ CORRUPTED BY REPRESSED SEXUALITY
}

Oscar R. Gómez oscar@tantra.org.es

Escuela Argentina de Tantra.

Cómo citar este artículo / Citation: Gómez, O. R. (2017). "Análisis crítico del Kularnava Tantra -Parte 1 - Un prólogo viciado de sexualidad reprimida". Revista Científica Arbitrada de la Fundación MenteClara, 2(1), 114-141.

DOI: $10.32351 /$ rca.v2.1.26

Copyright: (C) 2017 RCAFMC. Este artículo de acceso abierto es distribuido bajo los términos de la licencia Creative Commons Attribution-Non Commercial (by-cn) Spain 3.0. Recibido: 01/2/2017. Aceptado: 01/03/2017 Publicación online: $30 / 04 / 2017$

\section{Resumen}

Este artículo se realizó para promover una investigación académica del Kularnava Tantra sin el sesgo de los "prólogos" e introducciones de las versiones en inglés y español, que llevaron a la confusión del objeto de estudio denominado tantrismo.

Es intención del presente artículo instalar formalmente al tantrismo como filosofia/epistemología y presentar a los investigadores esta visión del hombre y la sociedad. Recogiendo la experiencia de la Casa de Tantra fundada en 1992 en Berazategui, provincia de Buenos Aires, se analizó la variación de las consultas recibidas de interesados de países de habla hispana para determinar la percepción que tenían del culto tántrico tibetano e hindú. De ese análisis surge que esta filosofia en tanto visión del mundo que era practicada como culto oficial en el Tíbet hasta el año 1959 y en la India, en secreto absoluto por cuestiones de persecución política y que ingresa a Occidente como palabra tantra fue mutando en el imaginario popular hasta convertirse en sinónimo de sexo lento y sin eyaculación. Esta mutación en la percepción de la población hispanoparlante proviene del prólogo escrito por Ramiro Calle para la edición en español del Kularnava Tantra. Es intención de este artículo proponer otra mirada sobre el texto para estimular su lectura con menor carga subjetiva. 


\begin{abstract}
This article was written to encourage academic research of the Kularnava Tantra without the bias included in the "forewords" and introductions of the English and Spanish versions, which led to a confusion of the object of study called Tantrism.

This article aims at establishing Tantrism as a philosophy/epistemology within formal education and introducing the techniques derived from this worldview to researchers. By recourse to the experience gained by the House of Tantra founded in 1992 in Berazategui, province of Buenos Aires, the change in the nature of inquiries by people from Spanish-speaking countries was analyzed in order to determine their perception of the Tibetan and Hindu tantric cult.

Out of such analysis, it was found that this philosophy as a worldview practiced as an official cult in Tibet until 1959, and in India, in absolute secrecy for political persecution reasons and which entered the West as the word tantra has been mutating in the social imagery until becoming a synonym of slow sex with no ejaculation.

This change in the perception of the Spanish-speaking population comes from the foreword written by Ramiro Calle for the Spanish language edition of the Kularnava Tantra. This article proposes to read the text under a different light to foster a less biased understanding.
\end{abstract}

\title{
Palabras Claves/ Keywords
}

Kularnava; tantra; tantrismo; budismo; jainismo; tántrico; sexo tántrico; Ramiro Calle; Arthur Avalon; estudios tántricos; religión; Mahavira; Panini; tantrism; Buddhism; Jainism; religion; tantric studies 


\section{Introducción}

El presente artículo tiene por objeto instalar un escalón más para que el tantrismo, en el mundo académico, alcance el estatus de categoría. Que pueda homologarse en las ciencias sociales el elemento tantra, tantrismo y sus derivados.

Si bien el cristianismo, el hinduismo, el islam son categorias politéticas (Urban, 1999) para definir al objeto tantrismo más que una definición politética encontramos definiciones antagónicas.

Por un lado, los trabajos académicos de fines del siglo XIX (Wilson, 1826) (Shiva, VII d.C) hasta el presente y, por otro, la demonización de la que fue objeto en India (Hayes, 2011) (Basu, 2016) y en Occidente, la distorsión provocada por una edición comercial, de divulgación popular, de una traducción al inglés hecha por Pandit (Pandit M, 1965) que recorta el texto original de 17 capítulos a tan solo 11 con el fin, según él declara, de resumirlo y realizar una versión libre para que sea entendida por la gente común; es decir, hace recortes y aportes de su propia visión teñida por esta demonización de la filosofia tántrica por parte del poder brahmánico.

Y en el mundo de habla hispana la distorsión se da, según entendemos, por la publicación en español de la traducción del libro en inglés de Pandit con introducción de Arthur Avalon más el agregado de un "prólogo" de Ramiro Calle (Pandit, 1980) al que en lugar de prólogo llama «ESTUDIO PRELIMINAR, EL CAMINO SECRETO DE LA ENERGÍA», que proyecta, tal como Arthur Avalon en la introducción, la propia comprensión dual del autor. 


\section{Metodología}

Para elaborar este análisis se emplearon: 1) el texto en sánscrito del Kularnava tantra conservado en el Rajshahi College ${ }^{1}$ (Shiva, VII d.C); 2) la edición en inglés del Kularnava Tantra con introducción de Arthur Avalon (Pandit M, 1965); 3) la edición en español, traducción íntegra de la mencionada obra en inglés por Govinda, más el "prólogo" de Ramiro Calle (Pandit, 1980) y 4) el trabajo de mineria de texto mediante $\mathrm{R} y$ analizado con Ghepi de Beatriz Valdez "Kularnava Tantra. Camino de circulación del significado" (Valdez, 2016).

Se realizaron entrevistas a quienes entre los años 80 y el presente se dedicaron a difundir o enseñar la filosofia tántrica en el mundo occidental. El cuestionario incluía las siguientes preguntas. A) ¿Cambió con los años la edad de las personas que se interesan por el tantrismo? ¿Se modificó el interés de las personas en aprender tantra? ¿'Se modificó la idea previa acerca del tantrismo de las personas interesadas? ¿Se modificó la búsqueda y lo que esperaban encontrar en una clase de tantra?

\footnotetext{
${ }^{1}$ El original, traducido por primera vez del sánscrito y publicado en inglés en 1878, contiene 2058 versos sobre muchos temas profundos, de los que solo una pequeña fracción trata sobre la relación maestro-discípulo ["guru-shishya"] que analizamos en este artículo. Esta traducción la terminaron en 1916 Sri M.P. Pandit y Sir Arthur Avalon en el norte de la India. Los pocos versos seleccionados por Pandit fueron editados por él para esa presentación que finalmente se publicó en 1965 y que es la edición cuestionada en este trabajo.
} 


\section{Desarrollo}

El Kularnava Tantra surge en el siglo VII de la era cristiana (Lorenzeti, 1992) influenciado y siguiendo el mismo estilo del Pancha Tantra (Wilson, 1826), es decir, forma parte de las colecciones denominadas en sánscrito nitizastras (Vishnu S. , 1949), que son textos destinados a la educación no solo política, o del político, sino que se extienden a las personas en general y llevan enseñanzas de carácter ético y moral al tiempo que una visión del hombre diferente a la establecida por los vedas.

Los vedas y el código de Manu (Zimmer, 2010), establecen la división de los hombres en castas sociales determinadas a priori del nacer y de las que el sujeto no puede salir.

La visión expresada en los textos tántricos es que el hombre puede superar su animalidad haya nacido en la casta que sea y elevarse en la sociedad. Es decir, iguala al momento de nacer a la totalidad de los hombres y les permite ascender en la posición social. Esto lo vemos reflejado en las sociedades ordenadas por el tantrismo mediante el siguiente ejemplo: Al llegar por primera vez al Tíbet en 1580 (Gómez, 2016), Antonio de Montserrat se sorprende y escribe "estas personas [que practicaban una religión -budismo tibetano- basada en un sincretismo entre el vajrayana traído por Padmasambhava (Fremantle, 1971) (XIV Dalai Lama, 1994) -tantrismo de las escuelas tántricas kaulas- y la religión bon] no tienen reyes entre sì (Sociedad Geográfica Española, 1998). 
Al hombre, por debajo de los dioses, por encima de los animales,

se le ha dado la razón como guía; A él no le impele la voluntad irracional como a las aves y animales;

A él no le mueve la poderosa Necesidad como los movimientos sin sentido de las cosas inconscientes.

El progreso furioso del gigante y el titán asciende para usurpar el reino de los dioses o merodea las magnitudes demoníacas del infierno;

En la pasión irreflexiva de sus corazones estrellan sus vidas contra la ley eterna y caen y se destrozan por su propia masa violenta; El camino de en medio está hecho para el hombre que piensa.

Escoger sus pasos por la luz vigilante de la razón, elegir su camino entre los muchos caminos, le es dado, a cada uno su dificil meta modelada de posibilidades infinitas.

(Sri Aurobindo: Savitri, VI-I)

Además del mencionado Pancha Tantra, del Hevajra Tantra (Snellgrove, 2011), del análisis del texto en sánscrito e hindi (Vishnu S. , 1952) (Vishnu S. , 1910), -de los pasajes referidos a la noción de verdad, de la liberación a través del gurú y de la ausencia de barreras de castasse desprende la influencia en el Kularnava Tantra del pensamiento de Mahavira, a través de los jainistas (Zimmer \& Campbell, 1953) y del gramático Panini (Glasenapp, 1999). 
No habiendo imprenta y pese a que un seguidor del camino kaula no debía violar ni siquiera las reglas de escritura -para garantizar la transmisión fiel de la enseñanza-, nos encontramos con que el Kularnava cuenta, al igual que todos los nitizastras, con versiones disimiles con to cual nos remitiremos a los aspectos donde hay coincidencias completas.

Dado que estas diferencias son en tanto las anécdotas para contar una misma conceptualización, nos decidimos por la mencionada versión conservada en el Rajshahi College.

No incluimos para este trabajo el análisis de las citas ni las notas al pie de Aurobindo Ghose -nacido en Calcuta en 1872 incluidas en las publicaciones en inglés de 1965 ni en español de 1980. No por no considerarlo un erudito en cuanto a tantrismo se refiere ya que sus textos enriquecen el saber acerca del tantrismo sino para enfocarnos en el análisis crítico del texto original del siglo VII.

Del análisis necesario para esta primera parte del trabajo encontramos que el texto propio del Kularnava Tantra -que no incluye el prólogo ni la introducción de Calle ni de Avalon- es coincidente en las versiones en inglés y español (Pandit M, 1965) (Pandit, 1980) con el original en sánscrito (Shiva, VII d.C) en los siguientes aspectos:

1) El texto es una suma de prohibiciones a las que un iniciado en el clan kaula debía someterse. Prohibiciones aún mayores a los que debían someterse los integrantes de otras órdenes inclusive la población en general más allá de la casta a la que pertenecieran. Encontramos una serie de leyes mucho más rigurosas que las leyes establecidas en los vedas.

2) El texto establece una verticalidad extrema entre los miembros del clan partiendo del gurú y establece que solo el sometimiento al gurú garantiza la liberación (Valdez, 2016). La verticalidad impuesta a los 
miembros del clan, al seguidor del camino kaula, es hacia los miembros más versados en la doctrina con independencia de la casta a la que éste perteneciera al momento de ingresar.

3) La aceptación como integrante del clan de candidatos de todas las castas, incluso los parias, con variaciones en cuanto al tiempo de admisión, pero con la salvedad de que una vez dentro del clan si hoy se iniciaba un paria y al día siguiente un brahmán, el brahmán debia servir al paria.

4) La realización de un ritual de adoración donde el iniciado debía quebrar cinco prohibiciones: Comer carne, tomar vino, comer cereales, comer pescado y adorar a una mujer. Son coincidentes con el original en sánscrito las versiones en inglés y español en que los alimentos que debían comer y la mujer que debian adorar se reemplazaban por otros. Entonces, el ritual no consistía en comer o hacer lo "prohibido" sino comer o efectuar una acción a modo de metáfora de la prohibición.

En relación al primer aspecto, la hipótesis que sostenemos es que con el propósito de no verse atacados directamente por el régimen opresor religioso y político imperante sobre las personas a las que el clan pretendia liberar se escudaron en prohibiciones aun superiores a las exigidas por el sistema para que no pudieran cercenar su tarea acusándolos de heréticos.

En relación al segundo aspecto, nos apoyamos en el análisis del gráfico de relaciones de Valdez obtenido en torno a los conceptos claves:

"Se observa que los circuitos presentes en la figura 2 se refieren a temas como verdad, supremo, suprema, ser, puede, shiva, shakti, gurú, liberación, conocimiento, mundo, forma, mantra y mente, 
plenitud, deidad, cuerpo, conciencia. El resto de los conceptos se unen a este núcleo".

Dice, además, Valdéz:

"Por último, nuestra interpretación del texto, que, reconocemos está influenciada por una visión tradicional del pecado y de la relación con los dioses ${ }^{2}$ es que: el gurú puede dar forma por un lado a la mente para, posiblemente asegurar su liberación; empleando el conocimiento para que surja el ser y la verdad en el mundo y para que el hombre descubra su deidad interior sobreponiéndose al pecado en armonía con los dioses... En concreto: el gurú es la llave para, a través del conocimiento y del deseo de Shakti, facilitar al hombre el descubrimiento de su deidad interior».

Por un lado, la verticalidad exigida para con el gurú quizá tenga que ver con la ausencia total de respeto humano y respeto por las ideas o la vida del otro reinante en la humanidad en ese período y casi hasta el tiempo presente y, por otro, como forma de asegurar la transmisión de una enseñanza ya que la liberación propuesta por el clan kaula no era la liberación espiritual-Moksha / मोक्ष - como se acota en el texto en inglés y en español sino Mukti / मक्तुि -en el texto original en sánscrito- y que es la liberación del yugo o de una carga muy pesada a la que estaban sometidas las personas, en especial los parias, y aquí el gurú es la garantía del conocimiento como liberador. Por lo tanto, único camino

\footnotetext{
2 Influencia que expresa también el propio editor de la traducción de Pandit al inglés al colocar en la solapa del libro de 1965: "Son traducciones libres -con anotaciones donde es necesario- omitiendo detalles técnicos pero preservando el espíritu y la importancia esencial del original..."
} 
posible. Solo alguien iluminado (letrado) puede elevar en el conocimiento de las leyes y sus derechos a un neófito.

El tercer aspecto tiene un carácter disruptivo en relación a los vedas, la ley y al resto de los escritos nitizastras aunque coincidentes con el pensamiento de Mahavira, Panini y los establecidos en el Pancha Tantra. De esa característica establecida en el Kularnava Tantra vemos un hombre emancipado de la "rueda de la reencarnación" y libre de los designios de la deidad establecidos por los vedas y es que cualquiera podia pertenecer al clan.

Solo los tiempos necesarios para ingresar podian mostrar cierta diferencia, pero no de casta -o del concepto de castas y reencarnaciónsino de patrimonio en tanto conocimiento.

En los tres años que le llevaba a un paria ingresar entendemos que primero debía aprender a leer, luego conocer la ley -los vedas- y luego la nueva ley. Un guerrero demoraba dos años en los cuales debía aprender la ley y luego, la nueva ley. Un brahmán demoraba un año ya que solo debía aprender la nueva ley, la ley que establecían los tantras, llamado también el Quinto Veda y, a nuestro entender, el nuevo evangelio iniciado por Mahavira o Buda si es que existió ya que ningún registro histórico fiable prueba la existencia del Buda.

Una vez dentro del clan, la jerarquía social estaba dada por el mérito y no por condición de nacimiento.

Éste es el único concepto disruptivo en relación al orden establecido por el poder político de ese período. Es la única violación a los usos y costumbres de la época, y es verdaderamente una subversión del orden social, una importante inversión de valores y la única, por otra parte, presente en el texto. 
Y en relación al cuarto aspecto, donde se relata la forma empleada en la adoración de la deidad mediante un ritual en el que el candidato debía quebrar cinco leyes, leemos en las tres versiones utilizadas para este análisis:

"Hay muchos tipos de ingredientes que se utilizan en la adoración de la Madre Divina. En el Kaulachara, comprenden: madya, vino; mamsa, carne; matsya, pescado; mudra, grano; y maithuna, mujen.

Como dijimos anteriormente, estos elementos no se consumían sino que se consumía un reemplazo a modo de metáfora; así, el vino se reemplazaba por leche de coco y la mujer, por una flor. Los tres textos son coincidentes, además, en:

"Y la mujer que debe atenderse no es otra que la Shakti interna, que permanece dormida en el animal humano normal y que está despierta en el seguidor del camino Kaula. Esta es la Shakti a la que se debe servir y asistirn.

El texto original del siglo VII continúa así: "El auténtico maithuna es integrar la shakti en uno. Cualquier otra cosa no es más que copulación".

Mientras que en las versiones en inglés y español, los textos siguen así:

"The rush of Ananda that ensues on the meeting of this Divine Pair, the Supreme Shakti and the Supreme Self, the Lord that waits above, that is the real maithuna, the final ma. Anything other is only copulation."

"El auténtico maithuna, la quinta "eme", es el flujo impetuoso de Dicha que sigue al encuentro de esta Pareja Divina, la Suprema Shakti con el Ser Supremo, el Señor que espera arriba. Cualquier otra cosa no es más que copulación". 
Como se ve, aparece aquí el agregado de las "aclaraciones del texto" teñidas de subjetividad teísta atravesada por la idea de un dios supremo, y sesgado por la idea de algo arriba al que debe ascenderse, el paraíso, el cielo, el padre.

Esta lectura es de muy compleja interpretación debido a que si consideramos que el candidato debía quebrar una ley, realizar un acto prohibido, nos encontramos con que ninguno de los cinco elementos utilizados en el ritual estaban prohibidos por ninguna religión, por el ordenamiento jurídico de la época, ni siquiera sus reemplazos. ¿A qué leyes se refiere, entonces, el Kularnava?

Nos encontramos que la influencia puesta de manifiesto en el texto en sí, despojado de los comentarios de los traductores y editores, incluso de Aurobindo, son los escritos de Mahavira, Panini y el Panchatantra.

Mahavira establece la noción de verdad relativa en su doctrina Anekāntavāda, -sánscrito अनेकान्तवाद, multilateralidad, verdad condicional- e instala en su doctrina el principio de incertidumbre y descreimiento de lo expresado en los vedas incluso en la idea del alma y la reencarnación. Panini menciona el termino GuruKaula para hacer referencia al maestro, a la casa del maestro. En el camino Kaula cualquiera podía ser maestro. Y el Pancha Tantra claramente asimila a las diferentes castas en una sola condición.

Por lo cual, entendemos que el Kaula es un camino que propone la unificación de las castas y la igualdad de todos los hombres. De hecho, como señalamos, en el Kularnava se establece que cualquiera podía ingresar al clan con la única condición de un tiempo determinado previo de estudios, pero una vez dentro la jerarquía era por mérito y no por condición de nacimiento. 
Estos conceptos de igualdad al momento de nacer y de meritocracia, son los que utilizó por primera vez en la historia conocida el Gengis kan -iniciado en el budismo tántrico- al nombrar como sucesor a su hijo menor Ogodei (Gómez, 2013), quien era el más capacitado para gobernar pese a no corresponderle por primogenitura.

Esta unificación de los hombres reunidos en igualdad de condiciones al momento de nacer requiere como condición necesaria el no ser nada a priori al momento del nacimiento.

Dentro de esta conceptualización, como podría meditar Mahavira, "quizá el alma no exista". Pues si existiera, si viniera de algún lado y con un fin, dependería de cada alma encarnada el estatus social en el que habia encarnado con lo que quedaría justificada la diferencia de castas y la idea de superioridad de unos sobre otros desde el nacimiento.

Aquí encontramos otra conceptualización disruptiva.

El yo soy que utiliza la New Age para justificarse en el repetir compulsivo de las mismas tonterias una y otra vez para mantenerse en la comodidad de lo conocido y que antes utilizaron los modelos teocráticos para mantener en la indignidad a los siervos de dios, a los guerreros, a los parias, a los campesinos -como en el Tíbet hasta 1959-, se cambia por el no soy; es decir, al momento de nacer no soy nada. Con lo cual, este texto abre las puertas al infinito potencial que existe en el hombre de ser lo que desee ser. La auténtica liberación.

Así, un simple nómade mongol que buscaba un rey para servirlo y ayudarlo a unificar las tribus se encontró con un monje tántrico que le dijo "somos todos iguales, ninguno es rey, con lo cual todos podemos serlo" y se liberó. Abandonó a su dios Tengri, se hizo cargo de su propia deidad, de la corona y se proclamó kan: El Gengis Kan (Gómez, 2008). 
Entonces, la noción de sujeto que atraviesa el Kularnava es la de un sujeto sujetado a la cultura, producido en ella y por ella.

Entendemos que las leyes que debía quebrar un iniciado en el clan eran las leyes en las que habian quedado instalados en el proceso de entronización (Berger \& Luckmann, 1968) y que lo limitaba en el camino de la liberación o su propia realización: mukti / मक्तुि en el texto original del siglo VII y moksha / मोक्ष en las versiones en inglés y en español.

Los iniciados debian quebrar leyes de su propia conducta como, por ejemplo, la genuflexión en un paria y el orgullo en un brahmán, de una manera similar a las propuestas por los clanes militares o por las escuelas conductistas hoy.

Esta noción de sujeto construido en la cultura, por lo tanto, iguales entre sí se extiende a la noción de lo masculino y lo femenino.

Lo masculino o femenino en este caso no son energias metafísicas como lo entendió Jung -que buscaba equilibrar lo que él llamó ánima y ánimus- o físicas como lo entendió Reich (Reich, 1990) ni atributos biológicos sino que son pautas o conductas que la sociedad reserva para uno u otro género y que un ser humano adopta balanceándose para uno $\mathrm{u}$ otro grupo de conductas de manera inconsciente y siempre a posteriori del nacimiento.

Con lo cual, el equilibrio o la libertad de elección, en cuanto a la realización de cada acto consciente, se da cuando se equilibran los aspectos masculinos y femeninos presentes en todos los seres con el fin de lograr armonía, equilibrio y estar así en posición de poder "destruir" en caso de que la situación lo requiera o "crear" si es oportuno, vencer por la fuerza -actitud que se atribuye típicamente a lo masculino- o por el amor, la seducción -actitud que se atribuye típicamente a lo femenino- 
como una elección meditada y consciente y no como un acto impulsivo propio de un animal.

Tal como dice Bhāskararāya Makhin, miembro del clan Kaula (Brooks, 1992): क्तिव और िक्ति का सौहाददपूर्दसंबंध, कौल है। "quien tiene dentro de si a Shiva $y$ Shakti es Kula".

Además, y ya hoy en la Argentina es un hecho jurídico el poder liberador del tantrismo, de la idea de no ser, que permite que un ser humano ni siquiera se limite a la condición biológica para configurarse de uno u otro género, pues quien haya nacido con sexo femenino, por ejemplo, puede legalmente convertirse en varón y cambiar su documento de identidad. Es decir, el tantrismo libera al hombre hasta de su propio nombre si así lo quisiera.

Esperamos ahora ofrecer nueva luz en la interpretación de la quinta eme, maithuna o "el maithuna" como se lo renombró recientemente.

Shakti, por otra parte, no es una forma metafisica de la consorte de Shiva, no es la convocatoria de fuerzas metanaturales o energías emanadas de otros "planos" sino la representación metafórica de un modelo de mujer, de una deidad ${ }^{3}$. Esta deidad es la propia femineidad interna presente en un iniciado en el tantrismo de la escuela Kaula.

\footnotetext{
${ }^{3}$ Pese a que infinidad de textos recientemente escritos sobre tantrismo -mal llamados textos "tántricos"- insisten en que la práctica tántrica consiste en adorar a la diosa, lo correcto sería decir deidad. Deidad en la cultura del período tántrico debiera asimilarse a lo que en ésta llamamos ídolos, modelos a seguir. Desde luego, convocar a alguien para convertirse en Dios o en Diosa es más rentable que utilizar la palabra deidad.
} 


\section{Análisis de la introducción y el "prólogo"}

Tanto las ediciones en inglés y en español están separadas en once capítulos y un apéndice; sin embargo, Arthur Avalon, en la introducción que presenta y firma en 1916, relata diecisiete capítulos de la obra y los analiza uno a uno con lo que muestra, por una parte, haber leído el texto original traducido al inglés en 1878, que tiene esa estructura, y, por otra, un total desconocimiento de la obra que finalmente se imprimió. Así finaliza su INTRODUCCION en la versión en inglés: "At the end of the seventeenth Chapter there is a remarkable passage... " (Pandit M, 1965) y en la versión es español "El capitulo dieciséis menciona los ritos hechos para alcanzar los diferentes objetos de deseo". (Pandit, 1980) siendo que la obra finalmente impresa en 1965 solo tiene once capitulos. La Editorial Eyras quitó el comentario de Avalon sobre el capítulo diecisiete.

En la página 20 de la introducción de Arthur Avalon de la edición de la Editorial Eyras se lee:

"En la presente edición se añaden datos de interés en notas a pie de página. Sin embargo, no pretendemos haber esclarecido todos los pasajes dificiles, pero las partes oscuras se han reducido hasta convertir la presente edición en un texto de trabajo".

¿Qué significa un texto de trabajo?

Aquí se observa la destrucción de la obra original para el mundo académico que no entienda el sánscrito, quedando reducido el texto fuente a la visión teísta, con aspiraciones de salvación espiritual y de verdades absolutas y a lo que él cree que pueden entender las personas «inferiores".

Dice en la página 22 al respecto de la "oscuridad" que él percibe: 
"Además, la senda Kaula está llena de peligros. Yo diría que también se compara el Vajrayana Budista con un bambú hueco en cuyo interior se coloca una serpiente. Esta debe ascender aun a riesgo de caer. Quien falle en este camino irá seguramente al infierno. Por ello, la criatura inferior debe evitar este método".

Dentro del texto en sí, no en la introducción que él escribe y en las tres versiones empleadas en este trabajo se lee: "cualquiera puede ingresar al clan", es decir, el Kularnava Tantra no separa a los hombres en superiores e inferiores. Además la noción de infierno no está presente en la obra en sánscrito.

En la página 23 de su introducción se lee:

"El capitulo quinto trata de la grandeza del Kula. Contiene la descripción de las sustancias Kaula. La fabricación del vino, las varias clases de vino, su uso como medio para la purificación de la mente y la conciencia, para que la mente pueda convertirse en Bramagah. Tras ello se enumera la doctrina fundamental de esta escuela: "el éxito se consigue con los mismos medios que conducen a la perdición". A continuación se habla de los sacrificios animales y la necesidad del vino y la carne en las diversas formas de adoración. "El brahmin debe tomar el soma según se ordena", ésta afirmación la niegan otros Tantras. Sin embargo, si se hace de forma animal, incluso los hombres superiores van al infierno".

Sin embargo, en el capítulo quinto de las traducciones al inglés y español nada de lo expresado está escrito. El capítulo quinto de esas traducciones versa, en coincidencia con el original en sánscrito, sobre las medidas previas a realizar rituales de adoración y aquí la palabra

\footnotetext{
${ }^{4}$ La negrita es nuestra.
} 
adoración hace referencia, una vez más, a la adoración de las propias cualidades internas o de un modelo externo -deidad, ídolo- para copiar. Es decir, lo que hace un adolescente cuando va modelando su persona.

Se lee en dicho capítulo las siguientes conceptualizaciones:

"1-La adoración debe realizarse en un lugar libre de distracciones e interrupciones, libre de multitudes...

2- Si hay transgresión de las reglas no hay frutos...

3-Y cuando el adorador comience el ritual, debe realizar y llegar al estado de conciencia en que se siente divino. Para comulgar realmente con la Divinidad y ofrecerse a Ella, uno debe hacerse consciente de su propio estado de divinidad. Un adorador así alcanza la Plenitud junto con la Liberación".

Del primer punto entendemos que las prácticas tántricas dentro del clan son individuales y en relación a procesos internos de cada practicante. No existe en el Kularnava Tantra ninguna práctica en pareja.

En el segundo párrafo, como a lo largo de todo el texto, se lee que al integrante del clan se le exigía un total acatamiento de las leyes establecidas. Y, en el tercer punto está claramente escrito que la liberación se lograba, desde esta doctrina, cuando el seguidor del camino kaula hace consciente su propia divinidad y se emancipa de las leyes opresoras de los vedas que lo mantenían sometido al estado permanente y hereditario de esclavitud e inferioridad.

Por esto, el tantra, a diferencia del yoga, que busca la liberación espiritual, busca la liberación de las cadenas de la esclavitud, la ignorancia y la superstición.

Es así que el juez británico Sir John George Woodroffe -quien se escudó detrás del seudónimo de Arthur Avalon para escribir sobre tantrismo 
seguramente por el preconcepto demoníaco que tenía del tantra- vería esto como el camino hacia la perdición..., del imperio y del dios reinante. Del infierno de su padre.

Para sobrevivir, aunque finalmente no lo lograron pues fueron exterminados en poco tiempo, los adeptos del clan kaula debieron someterse al sistema establecido, a la ley, a los vedas, con la intención de que, dentro del clan, los parias pudieran cobijarse, iluminarse, educarse y emanciparse uno a uno hasta cambiar la sociedad de castas. Emanciparse de la religión que los sometía, los esclavizaba, tal como emancipó el presidente Mao -quien se definió a sí mismo frente a su médico personal (Chhaya, 2009) y frente a SS el VIV Dalai Lama como seguidor del tantrismo- al pueblo tibetano de la terrible teocracia budista que exfoliaba a los campesinos del Tíbet.

Entendemos que con lo expuesto hasta ahora sobre la introducción de Avalon alcanza para mostrar la falta de visión crítica y objetiva de la obra en sí en el escrito introductorio que realiza de la edición en inglés que luego se tradujo al español y que fue la que más impactó en Occidente.

Por otra parte, en el "prólogo" 5 -1lamado "ESTUDIO PRELIMINAR. EL CAMINO SECRETO DE LA ENERGÍA»- de la edición en español (Pandit, 1980), Ramiro Calle, quien firma como Profesor de yoga de la Universidad Autónoma de Madrid -da clases de yoga en las horas libres a los alumnos de las distintas carreras de la universidad- dice en la página 10 respecto del tantrismo "aquel que confiere carácter de bondad a las convencionalmente "cinco cosas malas", entre otras la unión sexual".

\footnotetext{
${ }^{5}$ La palabra prólogo se mantuvo entrecomillada durante nuestro escrito ya que en la publicación cuestionada del año 1980 no figura la palabra prólogo como título del escrito de Calle. Si bien ocupa el lugar en donde debería ir el prólogo, su escrito lleva por título «ESTUDIO PRELIMINAR. EL CAMINO SECRETO DE LA ENERGÍA" y que lleva al lector a pensar que ya empezó a leer el texto del Kularnava Tantra.
} 
En ninguna de las tres versiones analizadas se menciona que el tantrismo confiere carácter de bondad a cosas malas, tampoco menciona como malas a los cinco objetos de adoración ni hace referencia al término unión sexual. La palabra unión sexual no se menciona en ninguna de las tres versiones del Kularnava Tantra (Valdez, 2016) y la palabra copulación se menciona una sola vez en las versiones en sánscrito, inglés y español en referencia a la quinta eme al decir que "la mujer que debe adorarse no es otra que la Shakti interna... cualquier otra cosa no es más

\section{que copulación".}

En la edición en español, unión sexual se menciona una y solo una vez en la página 10 del "prólogo" de Ramiro Calle pero no, en el texto en sí del Kularnava.

Sigue en la misma página: "No hay obligación ni prohibición, santidad ni pecado moral, cielo ni infierno para los adeptos del Kula". Nos preguntamos cómo es posible que una cultura que no estaba atravesada por las ideas del pecado mortal, del cielo y del infierno pudiera representarlas y luego negarlas. Entendemos que Ramiro Calle solo leyó la introducción de Avalon y tampoco lo entendió ya que el mismo Avalon no menciona en la introducción ningún rito de copulación.

Dice el "prólogo" de Calle en la página 13 de la edición en español:

"La inversión de valores la realiza el tántrico durante el rito de las "cinco cosas prohibidas", como práctica de potenciación de su energía primordial, de trascendencia, de integración con la Totalidad sin exclusión de nada. ¿Puede un cuerpo separarse de su sombra, saltar fuera de ella? La ingestión de los alimentos prohibidos (vino, carne, pescado y granos tostados: todos ellos con un rico simbolismo que puede utilizarse como soporte de cosmización) y la práctica del 


\section{acto sexual denominada maithuna y que exige control sobre los pensamientos, la respiración y el semen".}

En ninguna parte del texto en sí en ninguna de las tres versiones analizadas se menciona que deba realizarse la práctica del acto sexual, tampoco se menciona que durante el acto de adoración deba controlarse la respiración ni el semen. El término semen solo aparece una vez en la edición en español y es en el "prólogo" de letra de Ramiro Calle en la página 13 del libro de la Editorial Eyras.

El concepto controlar la respiración solo aparece en las tres versiones del texto en el capítulo VI y para referir que: de nada sirve al ser ni control de respiración ni yoga.

Sí hay una nota al pie del editor en ese capitulo que explica las técnicas de yoga que emplean el control de la respiración pero esta explicación para, según Avalon, "aclarar el texto" no forma parte del Kularnava Tantra.

El yoga era empleado para que pudieran estar felices los oprimidos con lo cual es consecuente que un iniciado ya no debía practicar yoga.

Dice también el prólogo: "que Kundalini despierte y haga posible la ascensión a planos más elevados -y libres de condicionamientos- de Conocimiento. La fuerza de la pasión se canaliza y se utiliza como trampolin hacia la Unidad".

Sin embargo, en el texto en sí no se menciona el término kundalini.

En la traducción española e inglesa del capítulo IV se lee: "En una declaración culminante de memorable importancia, el Kularnava afirma inequivocamente: Desde el Muladhara en la base asciende una y otra vez al Brahmarandhra en la parte alta. La felicidad surge de este encuentro de la Kundalini Shakti con la Luna de la Conciencia Puran. Claramente es un comentario del Kularnava y no el Kularnava Tantra en sí ya que esa 
frase "En una declaración culminante de memorable importancia, el Kularnava afirma..." seria como si el Quijote dijera "como dice el Quijote". Esta conceptualización no se encuentra en el original es sánscrito. Resulta evidente que la frase "declaración culminante de memorable importancia" está puesta para validar, para reafirmar, y que al lector -del "prólogo"- no le quede duda de que el tantra es alcohol, sexo y descontrol. Conceptualización que seguramente atraviesa el imaginario de Ramiro Calle y que, necesariamente, lo debe de sostener para sostener su ser védico y continuar siendo un maestro de yoga.

\section{Conclusión}

Hasta aquí el análisis introductorio y suficiente -para esta primer parte del trabajo-, de este texto para establecer cómo una "introducción» y un "prólogo" sesgado de un texto claro y distinto transformaron la percepción que occidente tiene de la palabra tantrismo.

El prólogo es escrito por alguien que no es el autor. Puede ser un experto en el campo, un escritor de un libro similar, alguien que simplemente conoce al autor.

El prefacio ayudar al editor en el marketing. Es la declaración de un autor eminente y mediático, que le da credibilidad al libro. Los prefacios ayudan al editor al estampar un sello de aprobación para que el libro sea bien vendido.

La introducción siempre está escrita por el autor y es siempre sobre el contenido del libro en sí, introduce al lector en lo que está ampliamente desarrollado en el libro. Los escritores eruditos usan a veces la introducción para incluir rápidamente el texto dentro de una disciplina particular o parte de ella y forma parte del libro en sí. Este último material 
es apropiado también para un prefacio pero debe aparecer en el prefacio o en la introducción, no en ambos.

Cuando el lector ingresa a las dos versiones, se encuentra con un capítulo del libro titulado "Introducción" y otro capítulo del libro titulado «ESTUDIO PRELIMINAR. EL CAMINO SECRETO DE LA ENERGÍA», y para el lector promedio son eso: capítulos del libro.

En ningún lugar del libro dice prólogo o prefacio para referirse a esos escritos; por lo tanto, el lector entiende que está leyendo el Kularnava Tantra, una autoridad en tantrismo y entre los seguidores del camino Kaula.

Probablemente, con la intención de vender lo que todos querrian comprar Avalon y Calle llamaron "Introducción" a lo que debía titularse prefacio y "ESTUDIO PRELIMINAR, EL CAMINO SECRETO DE LA ENERGÍA" a lo que debía titularse prólogo.

El texto conserva el registro del habla del siglo VII y, al ser, además, el Kularnava Tantra un texto encriptado y sin localización témporogeográfica alguna, es de dificil comprensión para el mundo académico occidental y, casi imposible para el público general, con lo cual, el lector que compró esas versiones en inglés y en español solo pudo entender lo que el Kularnava Tantra "dice» en la primera parte "ESTUDIO PRELIMINAR. EL CAMINO SECRETO DE LA ENERGÍA" y en la llamada introducción, ya que al intentar penetrar en el texto en sí, desde el primer párrafo solo puede ser comprendido con un conocimiento profundo de la historia y las filosofias de la India del período en el que se escribió. Para ese lector esa lectura será el Kularnava Tantra sin ninguna duda.

La introducción de Arthur Avalon, contaminada por su visión no advaita (dualista) cuerpo-alma, dios-el diablo, cielo-infierno, visión mágica, mística, propia de su estructura teísta, generó en Occidente la 
idea del tantra como una filosofia también mágica y mística destinada a la liberación del alma y que permite alcanzar una deidad externa.

La New Age, descreída de los líderes y de las instituciones propias de sus divinidades cristianas pero anhelante de la idea de salvación - que los estructuró-, encontró en la "filosofia tántrica» difundida en Occidente por Arthur Avalon la "llave secreta" y la "vía rápida" para alcanzar el paraíso y lo que el Occidente teísta entiende por éxtasis místico, como el de Juana de Arco. Solo que en vez de hablar con dios cara a cara, como ella, buscaban orgasmos cósmicos metafísicos.

Así es como hasta finalizando los 90, las personas que se acercaban al tantra lo hacian en una búsqueda genuina por encontrar una filosofia que se adaptara mejor a sus necesidades de progreso y expansión para encontrar la liberación de sus karmas.

De las entrevistas realizadas surge que en los 90 las personas se acercaban buscando una filosofia que cambiara su paradigma sabiendo que eso reportaría un cambio en su forma de relación, con el mundo y con los otros. Buscaban aumentar su capacidad de placer, incluso sexual, pero conscientes que eso no se daba realizando prácticas sexuales sino cambiando sus patrones mecánicos y su actitud frente a la vida.

Y lo que encontraron fue la liberación de la culpa de sus cuerpos "nacidos en pecado" y algunos, la excusa, proporcionada por los vendedores de ilusiones -gurúes- quienes, ayudados por el uso de drogas que ellos validaban, para dar rienda suelta a sus pasiones sin meditar consecuencias y otros se liberaron también pero de la excusa que les impedía amar con plenitud al otro cercano en vez de a una deidad intangible. 
Es decir, hasta finales de los 90, en el imaginario popular de Occidente, y gracias a la versión en inglés del Kularnava Tantra, se conceptualizó al tantra como una filosofia, una religión. Una forma de ser y percibir el mundo que no diferia de las otras filosofias de la India ni las prácticas del yoga pero que estaba sutilmente diferenciada de la gastada anterior ya que proponía la vía rápida de salvación -moksha-. Casi como un yoga comprimido instantáneo.

Con la aparición de la edición de Eyras en 1980, comenzó la difusión de ese libro en español. Y, quien compró esa versión no pudo entender otra cosa que no sea lo escrito en la primera parte del Kularnava Tantra llamada -en letras mayúsculas- "ESTUDIO PRELIMINAR. EL CAMINO SECRETO DE LA ENERGÍA».

Luego los lectores de esa edición, seguros de haber entendido perfectamente el Kularnava Tantra y conocer cuáles eran las prácticas tántricas, comenzaron a escribir notas sobre que el tantra exige la realización de "cinco cosas malas, una intencionada inversión de valores y la práctica del acto sexual llamado maithuna que exige el control de la respiración y el semen".

Esto se multiplicó en miles de escritos, periódicos, revistas y sitios web, y los medios repetían una y otra vez que el tantra era sexo lento y sin eyacular y ejecutar "el maithuna", un supuesto ritual donde un hombre y una mujer tienen sexo exótico tomando vino y comiendo cereales para alcanzar orgasmos cósmicos.

Este texto, el de la Editorial Eyras, cuyo fin al modificar el original seguramente fue vender el libro sin importar consecuencias, sirvió además para que las personas que se dedican a realizar trabajos sexuales -al estar prohibida la prostitución en muchos países- usaran la palabra tantra y maithuna para encubrir sus servicios de la misma manera que 
otros lo llaman "masajes" o "sauna" Así es como muchos sitios hablan del "masaje tántrico" como una forma de masaje que incluye el lingam -peney el yoni -vagina-. Para que las autoridades no los prohíban y los clientes que no pueden ni siquiera mencionar la palabra pene sin escandalizarse vayan a buscar "sexo sagrado", "sexo espiritual"

Es así como el tantra, que es un sistema filosófico, una doctrina, un modo de vivir y ver el mundo -en la enciclopedia Encarta del año 1998 se leía "Tantra: Religión oficial del Tíbet hasta 1959"- pasó a ser en el imaginario de las personas que hoy se acercan al tantra, y tal como surge de las entrevistas realizadas, una forma exótica de sexo sin eyacular para alcanzar orgasmos cósmicos. Se acercan para hacer grupalmente, o que le hagan, lo que sus conciencias no les permiten hacer sin excusas. Buscan una excusa para tener sexo sin compromiso y llamarlo sagrado.

Entendemos que esta conceptualización que existe hoy en el imaginario popular de simple sexo exótico aleja a quienes quieren indagar en las raíces del pensamiento europeo moderno que no es eurocéntrico. Aleja, además, a los niños, que si entendieran la filosofia tántrica, sus conceptos y técnicas individuales para modelar los esquemas emocionales y autogobernarse y gobernar su atención podrian transitar sus existencias más eficazmente.

Esperamos que este texto sirva de impulso para que otros estudiosos del tema puedan profundizar la lectura del Kularnava Tantra, utilizando la biografia que les presentamos, para colocarlo en el mismo nivel que los textos correspondientes a otras religiones o filosofias, como lo son la Torá, el Talmud, el Corán, los Evangelios, que claramente se agrupan en las categorias de judaísmo, islamismo, cristianismo, y que nos muestran una visión diferente del mundo que surgió en Oriente e influenció, al decir de Ghersom Sholem (Scholem, 2012) el pensamiento de las corrientes 
esotéricas más ortodoxas del judaísmo y del islam, así como la literatura (Foljambe, 2008), la filosofia y la política de Occidente.

Esperamos también que al categorizarse adecuadamente el tantrismo se acerquen quienes trabajan en desarrollar técnicas de intervención terapéuticas sustentadas en un modelo de sujeto que no está dividido en cuerpo y alma. Conocer el origen de esa idea, ese modelo. Y, conocer el origen de una idea y encadenarla con las subsecuentes ideas generadas a partir de ella, permite el continuo desarrollo del conocimiento académico.

\section{Referencias}

Basu, R. L. (2016). Aspectos científicos y beneficiosos del Culto tántrico. Revista Científica Arbitrada de la Fundación MenteClara| Tantra, 1(2), 26-49. Obtenido de http://fundacionmenteclara.org.ar/revista/index.php/RCA/article/view/15

Berger, P. L., \& Luckmann, T. (1968). La construcción social de la realidad. Amorrortu, ISBN 9789500180092.

Brooks, D. R. (1992). Auspicious Wisdom: The Texts and Traditions of Srividya Sakta Tantrism in South India. State Universisy New York Press, ISBN 9780791411469.

Chhaya, M. (2009). Dalai Lama. Hombre, monje, místico. Grijalbo.

Foljambe, A. (2008). Tantric Buddism, desire, and the bodyin surrealism and Georges Bataille. University of Manchester.

Fremantle, F. (1971). A Critical Study of the Guhyasamaja Tantra. London: University of London Library.

Glasenapp, H. v. (1999). Jainism: An Indian Religion of Salvation. Motilal Banarsidass Publ, ISBN 9788120813762.

Gómez, O. R. (2008). Manual de Tantra-desde el Tantra a la Tecnología del deseo (1º ed.). Buenos Aires, Argentina: Ediciones MenteClara, ISBN 978-987-24510-0-4 1.

Gómez, O. R. (2013). El tantrismo dentro de la Compañía de Jesús - del Tíbet al Vaticano hoy (Primera ed.). (F. MenteClara, Ed.) Buenos Aires, Argentina: Ediciones Menteclara. Recuperado el 1 de 11 de 2015 
Gómez, O. R. (2016). Antonio de Montserrat - La Ruta de la Seda y los caminos secretos del Tantra. Revista Científica Arbitrada de la Fundación MenteClara| Tantra, 1(1), 5-20. Obtenido de http:// fundacionmenteclara.org.ar/revista/index.php/RCA/article/view/8

Hayes, G. A. (2011). Tantric Studies: Issues, Methods, and Scholarly Collaborations. The Journal of Hindu Studies, 2011(4), 221-230.

Lorenzeti, D. N. (1992). Evidencia temprana de la religión tántrica. Estudios de Asia y Africa del Colegio de México, XXVII(2), 262-278.

Pandit M, P. (1965). Kularnava Tantra with Introduction by Arthur Avalon (1 ${ }^{\circ}$ ed.). Delhi, India: Motilal Banarsidass ISBN 0 89581-746-2.

Pandit, M. P. (1980). Kularnava Tantra. Rito de las cinco cosas prohibidas. Editorial Eyras.

Reich, W. (1990). La función del orgasmo: el descubrimiento del orgón. Problemas económico-sexuales de la energía biológica. Paidós, ISBN 9789688531044.

Scholem, G. (2012). Las grandes tendencias de la mistica judia. Buenos Aires, Argentina: SIRUELA ISBN: 9788478443130.

Shiva, L. (VII d.C). Kularnava Tantra o Urdhvaamnaaya Tantra (Reimpresión del original conservado en el Rajshahi College en Sanskrit in Bengali typeset with Bengali Translation). (U. K. Das, Ed.) Calcuta, India: Ranjit Saha, NavBharat Publishers 1976.

Snellgrove, D. (2011). The Hevajra Tantra: A Critical Study. Orchid Press, ISBN 978-9745241282.

Sociedad Geográfica Española. (1998). Antonio de Montserrat: En la última frontera. Boletín $N^{o} 43$ de la SGE. Recuperado el 2015, de http://www.sge.org/sociedad-geograficaespanola/publicaciones/boletines/numeros-publicados/boletin-no-43/antoni-de-montserraten-la-ultima-frontera.html

Urban, H. B. (1999). The extreme orient: the construction of 'tantrism'as a category in the orientalist imagination. Religion, 29(2), 123-146.

Valdez, B. (2016). Kularnava Tantra, Camino de circulación del significado. Revista Científica Arbitrada de la Fundación MenteClara| Tantra, 1(1), 227-247. Obtenido de http://fundacionmenteclara.org.ar/revista/index.php/RCA/article/view/13

Vishnu, S. (1910). Pancha Tantra- Hindi-. Bombay, India: Srivenketeshwar Steem Press.

Vishnu, S. (1949). Pancha Tantra o cinco series de cuentos. (J. A. Bolufer, Trad.) Buenos Aires, Argentina: Partenon.

Vishnu, S. (1952). Pancha Tantra -Sánscrito-. Bombay, India: khemraj Shrikrishnadas Venkateshwar Steam Press.

Wilson, H. H. (1826). Analytical Account of the Pancha Tantra, Illustrated with Occasional Translations. Transactions of the Royal Asiatic Society of Great Britain and Ireland, 1(2), 155200.

XIV Dalai Lama, T. G. (1994). Tantra de kalachakra - Rito de iniciacion. España: DHARMA, ISBN 9788486615468.

Zimmer, H. (2010). Filosofias de la India. SEXTO PISO, ISBN: 9788496867642.

Zimmer, H., \& Campbell, J. (1953). Philosophies Of India. London: Routledge \& Kegan Paul Ltd ISBN 978-81-208-0739-6. 